\title{
Temperature Control in Spark Plasma Sintering: An FEM Approach
}

\author{
G. Molénat, ${ }^{1,2}$ L. Durand, ${ }^{1,2}$ J. Galy, ${ }^{1}$ and A. Couret ${ }^{1}$ \\ ${ }^{1}$ CNRS - CEMES (Centre d'Elaboration de Matériaux et d'Etudes Structurales), 31400 Toulouse, France \\ ${ }^{2}$ Université Paul Sabatier, Toulouse, France \\ Correspondence should be addressed to L. Durand, lise.durand@cemes.fr
}

Received 29 September 2009; Accepted 6 January 2010

Academic Editor: Brij Kumar Dhindaw

Copyright ( $) 2010$ G. Molénat et al. This is an open access article distributed under the Creative Commons Attribution License, which permits unrestricted use, distribution, and reproduction in any medium, provided the original work is properly cited.

\begin{abstract}
Powder consolidation assisted by pulsed current and uniaxial pressure, namely, Spark Plasma Sintering (SPS), is increasingly popular. One limitation however lies in the difficulty of controlling the sample temperature during compaction. The aim of this work is to present a computational method for the assembly temperature based on the finite elements method (FEM). Computed temperatures have been compared with experimental data for three different dies filled with three materials with different electrical conductivities ( $\mathrm{TiAl}, \mathrm{SiC}, \mathrm{Al}_{2} \mathrm{O}_{3}$ ). The results obtained are encouraging: the difference between computed and experimental values is less than 5\%. This allows thinking about this FEM approach as a predictive tool for selecting the right control temperatures in the SPS machine.
\end{abstract}

\section{Introduction}

1.1. The SPS Process. SPS (Spark Plasma Sintering) consists in applying a pulsed current and a uniaxial pressure, and thus allows high compaction rates and level, particularly for materials that are difficult to densify. This also leads to the formation of original microstructures and materials with outstanding or new properties. In a recent review of SPS, Munir et al. [1] reported a dramatic increase in the number of papers on this subject or on materials sintered with it. SPS also raises numerous fundamental questions: which physical mass transport mechanisms control particle powder welding? Also investigated in the literature by Munir et al. [1] and Conrad et al. [2] are the issues of plastic deformation, electroplastic deformation, electromigration, spark plasma, or electric arcs at the particle. Surely, the right explanation will depend on the kind of powder involved, particularly electrical conductivity compared to that of the die: densification is expected to take a different form depending on whether the current flows through the powder or through the die. Note that it is the unconfirmed hypothesis of plasma formation which leads to the commercial name SPS. Pulsed Electric Current Sintering (PECS) which is sometimes found in the literature would seem more appropriate, but SPS has apparently been the accepted name.
1.2. Temperature Control. Figure 1 shows a schematic drawing of SPS apparatus used in the present study. Depending on die and sample geometries, and on electrical resistivities, current lines will spread in different ways. Therefore, highly different temperature fields can be generated in the set-up. In particular, in the powder volume, temperature can be inhomogeneous, especially if the volume is high or complex. Can these internal temperatures be known? This paper addresses this issue. Pyrometric measurements yield the temperature of the external die wall. By placing thermocouples inside the holes at different depths, some local internal die temperatures can also be measured. However, the measurement inside the sample remains problematic: inserting a thermocouple is a local and destructive procedure. Indirect measurement could be considered by observing phase transformations. In this case the results would probably lack accuracy and it would only be possible to determine whether a temperature corresponding to a known phase transformation temperature has been exceeded. Three other limitations can be seen: (i) phase transformation temperatures are known for equilibrium configurations, whereas typical SPS sintering is a fast process occurring out of equilibrium; (ii) this approach requires materials with phase transformations; (iii) as with thermocouples, it is destructive. To address the 


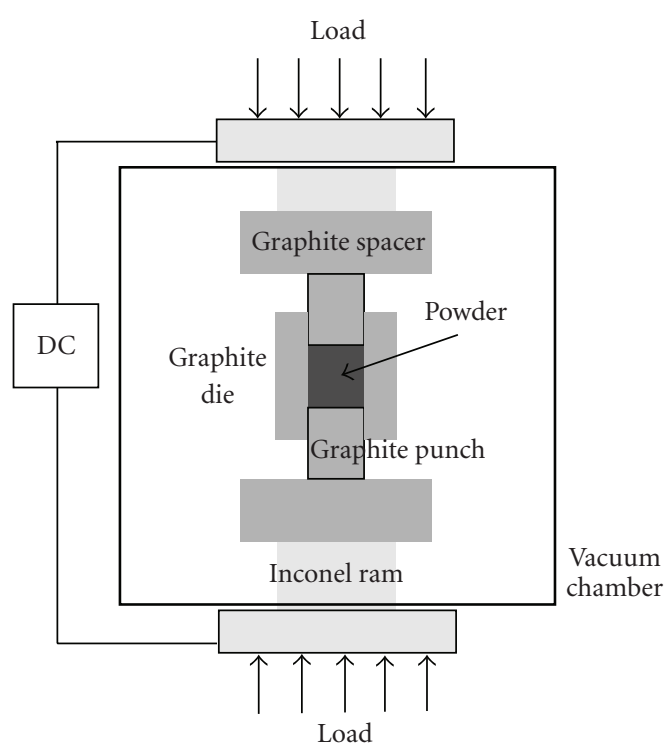

FIgURE 1: Schematic drawing of the SPS process.

key issue of sample temperature control, a solution might be to compute the temperatures of interest which could then be compared to those measured, thus leading to a predictive tool for selecting the right control temperature of the SPS machine, for any geometry or powder. Based on this approach, this paper aims at presenting our first results in the case of three different materials and geometries.

\section{State of the Art}

Determining the temperature field inside an SPS set-up is not a new concern. Through analytical calculations based on the heat equation, Yucheng and Zhengyi [3] found a difference of $345^{\circ} \mathrm{C}$ between the edge and the centre of a $\mathrm{TiB}_{2}$ sample, compared with an experimental difference of $450^{\circ} \mathrm{C}$. The order of magnitude is correct within the approximation made, and the difference between calculations and measurements can be accounted for the simplifications introduced and by the fact that unlike experimental conditions the calculated results correspond to stationary state. Matsugi et al. [4] developed a finite difference method (FDM) for coupling heat and electricity equations. From an experimental point of view, they placed thermocouples into punches, die, and samples with a conductive powder (Ti) and an insolating one $\left(\mathrm{Al}_{2} \mathrm{O}_{3}\right)$. In these experiments, the stationary state was reached. The difference between calculations and experiments did not exceed $10^{\circ}$. Zavaliangos et al. [5] employed an FEM approach (ABAQUS code) for calculating the temperature of a graphite sample inside a graphite die. Taking into account thermal resistances between die and sample, a good fit was achieved between calculated and experimental differences of temperatures $\Delta T$ between the external wall die and the centre of the sample. AnselmiTamburini et al. [6] also made use of FEM calculations (CFD code) disregarding in this case thermal resistances. With an $\mathrm{Al}_{2} \mathrm{O}_{3}$ sample, the calculated $\Delta \mathrm{T}$ was $27 \%$ lower than the experimental temperature but absolute values were significantly different: the calculated ones were $200^{\circ} \mathrm{C}$ lower than the measured ones. Lastly, Vanmeensel et al. [7] used another FEM code (ANSYS) taking into account the contact resistances on the basis of many specific experiments. A good agreement was obtained between calculations and experiments for a graphite sample in the graphite die: the calculated $\Delta T$ was $4 \%$ lower than the experimental one.

\section{Methodology}

3.1. The SPS Machine. A Dr. Sinter 2080 SPS apparatus was used in this work (Sumitomo Coal Mining Co., Japan), which is installed in the "Plate-forme Nationale de Frittage Flash/CNRS" in Toulouse (PNF2/CNRS-MHT, Paul Sabatier University, Toulouse, France). Pulse duration was $3.3 \mathrm{~ms}$, and a pulse sequence consisting of twelve pulses followed by two periods of zero current was selected.

3.2. Temperature Measurements. To test our calculations in various configurations, specific SPS experiments were carried out with three cylindrical geometries and three materials (Figure 2): a conducting material TiAl (electrical resistance $\rho_{e}=6 \cdot 10^{-7} \Omega \cdot \mathrm{m}$ at $\left.300 \mathrm{~K}\right)$, an insulating material $\mathrm{Al}_{2} \mathrm{O}_{3}\left(\rho_{e}\right.$ $=10^{8} \Omega \cdot \mathrm{m}$ at $300 \mathrm{~K}$ ), and a material with an intermediate conductivity $\operatorname{SiC}\left(\rho_{e}=2 \Omega \cdot \mathrm{m}\right.$ at $\left.300 \mathrm{~K}\right)$, referred to as "TiAl", " $\mathrm{Al}_{2} \mathrm{O}_{3}$ ", and " $\mathrm{SiC}$ " geometries, respectively. A point in space is defined by the radial distance $r$ (e.g., the vertical edge of the TiAl sample is $r=18 \mathrm{~mm}$ ) and the longitudinal distance (height) $h$, the origin of $h$ being taken as half the height of the assembly, that is, at the level of the axial symmetry plane. For the TiAl geometry, temperature measurements were obtained by microstructure characterization of the sample, using scanning electron microscope (SEM) observations: this intermetallic alloy exhibits a phase transformation which can be identified and correlated to $\alpha \rightarrow \alpha+\gamma$ transus temperature. Note that with this geometry, temperature was controlled during sintering by a pyrometer focused at $h=$ 0 at the back of a $3 \mathrm{~mm}$ depth hole, that is, $r=32 \mathrm{~mm}$. For the $\mathrm{Al}_{2} \mathrm{O}_{3}$ geometry, local temperatures were measured by a K-thermocouple placed into similar holes. For $h=0$, thermocouples were placed at $r=6,11,16$, and $22 \mathrm{~mm}$, respectively. For $r=22 \mathrm{~mm}$, measurements were also carried out above $(h=+5 \mathrm{~mm})$ and below $(h=-10 \mathrm{~mm})$. As far as the $\mathrm{SiC}$ geometry is concerned, measurements were performed at $h=0$ with thermocouples at $r=13$ and $22 \mathrm{~mm}$, but also inside the sample with a specific platinum thermocouple at $r=0$.

\subsection{Calculation}

3.3.1. Calculation Principles. For each point of the solids and each time $t$, the local equations of electricity (a) and heat (b) had to be verified:

$$
\begin{gathered}
\nabla \cdot(\nabla V)=0 \\
\nabla \cdot(-\lambda \nabla T)+\rho C_{p}\left(\frac{\partial T}{\partial t}\right)=\sigma(\nabla V)^{2},
\end{gathered}
$$




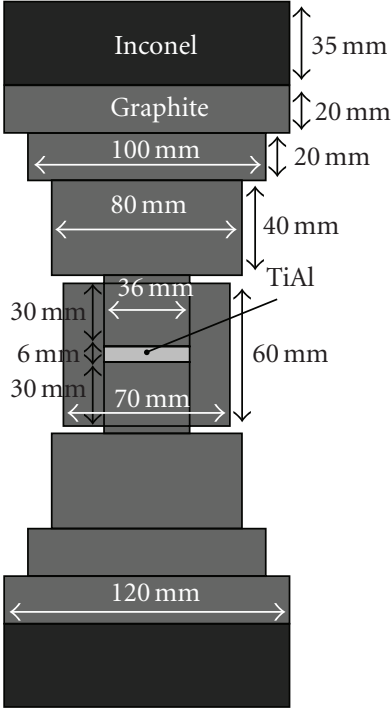

(a) TiAl sample

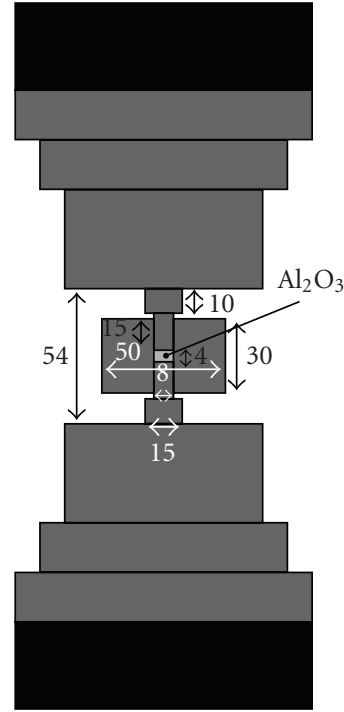

(b) $\mathrm{Al}_{2} \mathrm{O}_{3}$ sample

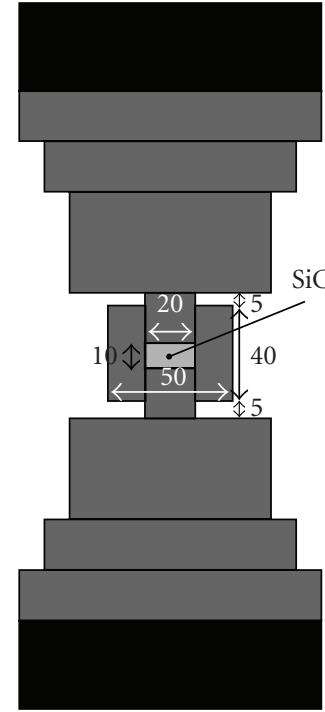

(c) $\mathrm{SiC}$ sample

FIGURE 2: The three experimental configurations (schematic drawings at the same scale).

where $V$ is the electrical potential, $T$ the temperature, and $\lambda, \rho, C_{p}$ and $\sigma$ are the thermal conductivity, mass density, thermal capacity, and electrical conductivity of the material, respectively. These four parameters, related to the three materials studied and to inconel and graphite, are given in Table 1 as a function of temperature.

From a mathematical view point, these two second-order differential equations have to be coupled each time with respect to the three coordinates. The heat source (right term of (b), does present an electrical origin as described by (a). Solving this equation system at every time and at every points of the assembly requires using a numerical approach based on finite differences or finite elements. Here, the finite elements method has been retained.

\subsubsection{Simplifying Hypothesis. The general form of the local} electricity equation is $\nabla \cdot(\nabla V)=-(1 / \sigma) d \rho_{q} / d t$, where $\rho_{q}$ is the charge density. When time increases, temperature equally rises just like the charge density, especially in the $\mathrm{SiC}$ semiconductor. However, one has to consider that $\rho_{q}$ is a constant value even in this case. Another simplification is that all data in Table 1 correspond to massive materials, not powders. This is not problematic for $\mathrm{Al}_{2} \mathrm{O}_{3}$ and $\mathrm{SiC}$ since the corresponding temperature measurements have been achieved with massive samples placed in the die. For TiAl, the situation is different because powder has been compacted during experiment. Thus only those temperatures reached at the end of compaction have been taken into account for the purpose of comparison with calculations. As for TiAl, the material has been assumed to be stable without any phase transformation, and this is contrary to reality. Also transformation heats have been disregarded and the temperature dependence of $\lambda, \rho, \mathrm{C}_{p}$, and $\sigma$ has been determined as if temperature had always remained below the $\alpha_{2}+\gamma \rightarrow \alpha+\gamma$ transus temperature. On the other hand, for both $\mathrm{Al}_{2} \mathrm{O}_{3}$ and $\mathrm{SiC}$, phase transitions do not exist in the temperature range of our experiments.

Electrical and thermal contact resistances, especially between die and punches, have been ignored. It has been shown by Zavaliangos et al. [5] and Vanmeensel et al. [7], that they can play an important role but they are highly dependent on surface states or applied pressures. For example, Anselmi-Tamburini et al. [6] have demonstrated that if the applied pressure is higher than $50 \mathrm{MPa}$ (our situation), electrical resistance of the graphite assembly is similar to the one of a graphite block with the same geometry. Moreover, incorporating these resistances would require specific measurements for each experiment to be simulated. As our goal has been to get a simplistic predictive tool, we have disregarded them and preferred to investigate $a$ posteriori the influence of this choice. As will be shown in Section 5 giving calculated and measured temperatures, this seems reasonable. The same goal prompted us to ignore the $0.2 \mathrm{~mm}$ width graphite paper located on the internal die wall to facilitate sample removal. In the particular case of $\mathrm{Al}_{2} \mathrm{O}_{3}$ and $\mathrm{SiC}$ geometries, we ignored the influence of thermocouples and the holes drilled in the sample.

Voltage is made up of pulses but, as shown by AnselmiTamburini et al. [6], the period involved is long enough for modelling this signal by a continuous function. In our experiments, this function starts from 0 at time zero and increases up to a stage with permanent fluctuations imposed by the machine for following the temperature ramp imposed. In our calculations, a direct and constant voltage has been used as time starts with a value corresponding to the experimental value reached at the final stage of the experiment. 
TABLE 1

(a) Materials data.

\begin{tabular}{lccc}
\hline & & Inconel 600 & Graphite [7] \\
\hline Thermal capacity & $\mathrm{C}_{p}\left(\mathrm{~J} \cdot \mathrm{kg}^{-1} \cdot \mathrm{K}^{-1}\right)$ & $344+2.5010^{-1} \mathrm{~T}[2]$ & $34.27+2.72 \mathrm{~T}-9.610^{-4} \mathrm{~T}^{2}$ \\
Thermal conductivity & $\lambda\left(\mathrm{W} \cdot \mathrm{m}^{-1} \cdot \mathrm{K}^{-1}\right)$ & $10.09+1.5710^{-2} \mathrm{~T}[13,14]$ & $82.85-0.06 \mathrm{~T}+2.5810^{-5} \mathrm{~T}^{2}$ \\
Electrical resistivity & $\rho_{e}(\Omega \cdot \mathrm{m})$ & $9.8210^{-7}+1.610^{-10} \mathrm{~T}[13,14]$ & $2.1410^{-5}-1.3410^{-8} \mathrm{~T}+4.4210^{-12} \mathrm{~T}^{2}$ \\
Density & $\rho\left(\mathrm{kg} \cdot \mathrm{m}^{-3}\right)$ & $8430[14]$ & $1904-0.01414 \mathrm{~T}$ \\
\hline
\end{tabular}

(b)

\begin{tabular}{lcccc}
\hline & & $\mathrm{TiAl}$ & $\mathrm{SiC}$ & $\mathrm{Al}_{2} \mathrm{O}_{3}$ \\
\hline Thermal capacity & $\mathrm{C}_{p}\left(\mathrm{~J} \cdot \mathrm{kg}^{-1} \cdot \mathrm{K}^{-1}\right)$ & $583+0.094 \mathrm{~T}[15]$ & $670[16]$ & $850[17]$ \\
Thermal conductivity & $\lambda\left(\mathrm{W} \cdot \mathrm{m}^{-1} \cdot \mathrm{K}^{-1}\right)$ & $9.47+1.1910^{-2} \mathrm{~T}[18]$ & $411 \mathrm{e}^{-0.0025 T}[16]$ & $39500 \mathrm{~T}^{-1.26}[17]$ \\
Electrical resistivity & $\rho_{e}(\Omega \cdot \mathrm{m})$ & $4.0610^{-7}+6.4510^{-10} \mathrm{~T}[19]$ & $4.5 \mathrm{e}^{-0.0027 T}$ & $8.710^{19} \mathrm{~T}^{-4.82}$ \\
Density & $\rho\left(\mathrm{kg} \cdot \mathrm{m}^{-3}\right)$ & 3900 & 3200 & 3899 \\
\hline
\end{tabular}

3.3.3. Limit Conditions. With respect to the heat flux, the following limit conditions have been imposed:

(i) for vertical walls: radiative heat flux $\Phi_{r}=\sigma_{s} \cdot \varepsilon \cdot\left(T_{e}^{4}-\right.$ $T_{a}^{4}$ ) with $\sigma_{s}=$ the Stefan-Boltzmann's constant, $\varepsilon=$ graphite emissivity $(\varepsilon=0.8$ from [7] $), T_{e}=$ emission surface temperature (graphite), and $T_{a}=$ absorption surface temperature (chamber walls) $=300 \mathrm{~K}$

(ii) for horizontal walls:

(a) conducto-convective heat flux for the two Inconel surfaces in contact with cooling water, that is, $\Phi_{c}=h c \cdot\left(T_{i}-T_{w}\right)$ with $h_{c}=$ conductoconvective coefficient $\left(h_{c}=880 \mathrm{~W} \cdot \mathrm{m}^{-2} \cdot \mathrm{K}^{-1}\right.$ from [7]), $T_{i}=$ Inconel horizontal wall temperature, and $T_{w}=$ water temperature $=300 \mathrm{~K}$.

(b) Taking into account the assembly symmetry, it has been considered that for opposite horizontal surfaces, emitted and absorbed fluxes are counterbalanced.

3.3.4. MEF Calculations. The COMSOL code featuring a tetrahedral mesh has been used. This kind of mesh is not as efficient as a cube one. However, it provided the required calculation convergence. The initial condition for temperature is obviously $T=300 \mathrm{~K}$ (uniformly). Voltage is only known at the two Inconel extreme surfaces: $0 \mathrm{~V}$ on the bottom surface and the imposed voltage on the top surface. Thus, different voltage distributions within the assembly were tested:

(i) linear variation between bottom and top,

(ii) linear variation of $0.5 \mathrm{~V}$ in the two inconel rams plus linear variation from 0.5 to 4.5 between them,

(iii) linear variation of $0.5 \mathrm{~V}$ in the two inconel rams plus variations for each graphite pieces taking into account their size differences, in consistency with Ohm law.

As a simple linear distribution was found to yield the same results as the other distribution, it was selected. The amplitude of voltage between the bottom and top imposed as an initial condition is derived from experiment as shown below.

To take into account time dependence $(\partial T / \partial t$ term in heat equation), calculations have been made step by step, each step corresponding to a time increment. Therefore, a calculation corresponds to the progressive temperature rise at each point of the assembly. A sufficiently high step number permits to reach a stationary state.

\section{Results}

\subsection{Measured temperatures}

4.1.1. TiAl. A $\mathrm{Ti}_{49} \mathrm{Al}_{47} \mathrm{Nb}_{2} \mathrm{Cr}_{2}$ powder prepared by gas atomisation has been used. The SPS conditions (temperature and pressure ramps) selected for compacting this alloy terminate in a 2-minute holding time at $1190^{\circ} \mathrm{C}$ (this is the control temperature measured by the pyrometer) [8]. The corresponding voltage during this final stage was $4.2 \mathrm{~V}$. Figure 3(b) shows the sample microstructure at $r=9 \mathrm{~mm}$, that is, at half the distance between the centre $(r=0)$ and the vertical edge of the TiAl billet $(r=18 \mathrm{~mm})$. This microstructure is made of small dark contrasted grains with a $\gamma$ structure and bigger grains with a clear streaked contrast, the so-called lamellar grains. This kind of lamellar grains corresponds to a coherent juxtaposition of very thin lamellae, either ordered $\alpha_{2}$ phase or $\gamma$ phase $[9,10]$. Such a microstructure with dominant lamellar grains is obtained for temperatures slightly lower than the $\alpha \rightarrow \alpha+\gamma$ transus temperature, that is, $1330^{\circ} \mathrm{C} \pm 10$ [11]. Figure $3(\mathrm{a})$ shows the microstructure of the same sample at $r=0$. It appears that grains are very large and lamellar. This microstructure could only be obtained if temperature is higher than the $\alpha \rightarrow \alpha+\gamma$ transus temperature. So, for a sample sintered at $1190^{\circ} \mathrm{C}$, the temperature reached is lower than $1330^{\circ} \mathrm{C}$ at $r=9 \mathrm{~mm}$ and higher than $1330^{\circ} \mathrm{C}$ at $r=0: 1330^{\circ} \mathrm{C}$ is attained somewhere between these two places, that is, around $r=4.5 \mathrm{~mm}$. In this case, the difference between the sample 


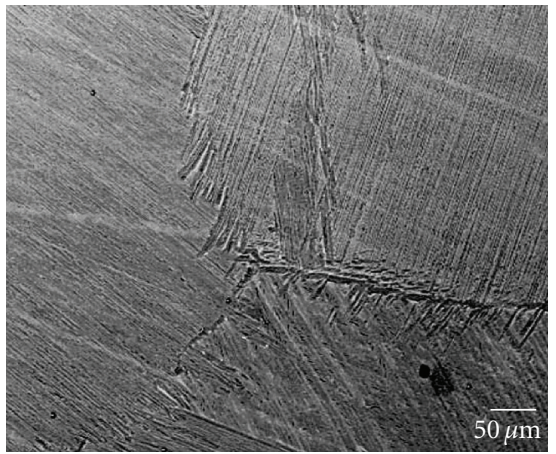

(a) $1190^{\circ} \mathrm{C}$ and $r=0$

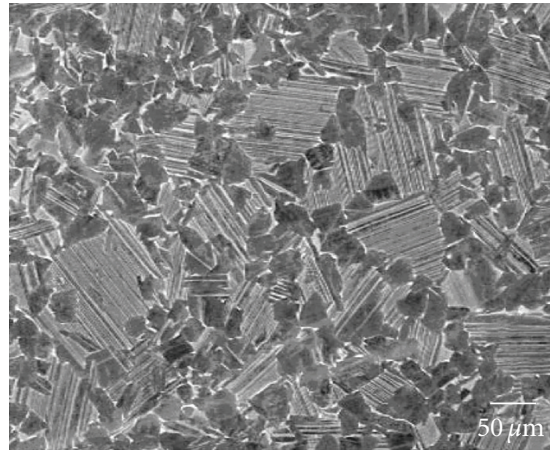

(b) $1190^{\circ} \mathrm{C}$ and $r=9 \mathrm{~mm}$



(c) $1175^{\circ} \mathrm{C}$ and $r=0$

Figure 3: TiAl microstructures observed by SEM in samples sintered at pyrometer temperatures of $1190^{\circ} \mathrm{C}$ and $1175^{\circ} \mathrm{C}$.

temperature at $r=4.5 \mathrm{~mm}$ and the temperature measured where the pyrometer is focused $(r=32 \mathrm{~mm})$ is $140^{\circ} \mathrm{C} \pm 10$.

In another experiment for which sintering temperature was $1175^{\circ} \mathrm{C}$ (Figure 3(c)), the microstructure at $r=0$ was the same as at $1190^{\circ} \mathrm{C}$ at $r=9 \mathrm{~mm}$. In other words, for a compaction with a temperature $15^{\circ}$ lower, the temperature at the centre has not reached $1330^{\circ} \mathrm{C}$. A $15^{\circ}$ rise of the external temperature seems thus to produce a rise of the same order of the centre temperature. From these findings, it follows that the temperature difference between the centre of the sample and its vertical edges is approximately $2 \times 15=30^{\circ}$. This is consistent with what has been observed by Couret et al. [12] for homogeneous microstructures along the sample radius with a sintering temperature in the $\alpha+\lambda$ region.

4.1.2. $\mathrm{Al}_{2} \mathrm{O}_{3}$. Figure 4 (a) shows the temperatures measured in the graphite die at $h=0$ and $r=22,16,11$, and $6 \mathrm{~mm}$, respectively, during an experiment where temperature has been increased in five stages. The temperature rises from the external wall of the die to the internal one. Figure 4(b) shows the same kind of measurements with thermocouples placed at the same radial distance $(r=22 \mathrm{~mm})$ and at different heights: $h=0,+5$ and $-10 \mathrm{~mm}$, respectively. The temperature decreases symmetrically with respect to the symmetrical plane of the assembly $(h=0)$. In both cases, the temperature ramp was the same, the controlling temperature was measured by the thermocouple situated at $r=3 \mathrm{~mm}$ and the five voltages reached were successively $1.4 \mathrm{~V}, 2.1 \mathrm{~V}, 2.8 \mathrm{~V}$, $3.5 \mathrm{~V}$, and $4.4 \mathrm{~V}$.
4.1.3. SiC. Measurements in $\mathrm{SiC}$ (Figure 5) were made in the graphite die at $h=0$ and at different depths $(r=13$ and $22 \mathrm{~mm})$ but also in the material itself $(r=0)$. The four short stages during temperature rise are associated with four voltages: $2.4,3.0,3.6$, and $4.2 \mathrm{~V}$, respectively. As in the $\mathrm{Al}_{2} \mathrm{O}_{3}$ cases, the temperature rises from the external wall of the die to the internal one.

\subsection{Calculated Temperatures}

4.2.1. TiAl. The value of the voltage imposed as the initial condition in our calculations is $4.2 \mathrm{~V}$, that is, the value reached at holding time during the sintering at $1190^{\circ} \mathrm{C}$ (Section 4.1.1). Figure 6 shows the radial variation of temperature in the horizontal symmetry plane for one over ten calculated steps, which correspond to the time and temperature increments (see Section 3.3.4). It shows that the number of steps was high enough to reach the stationary state. The step which yielded a temperature of $1190^{\circ} \mathrm{C}$ was selected. Note that $1190^{\circ} \mathrm{C}$ was reached before the last step, the stationary value being $1581^{\circ} \mathrm{C}$. At this step, the temperature field is given in Figure 7(a). In Figure 8, plot (a) is derived from this field. It represents the radial variation of temperature $T(r)$ at $h=0$, where the pyrometer is placed. From this plot, the calculated temperature at $r=0$ and $9 \mathrm{~mm}$ can be compared to the experimental values given in Section 4.1.1. 


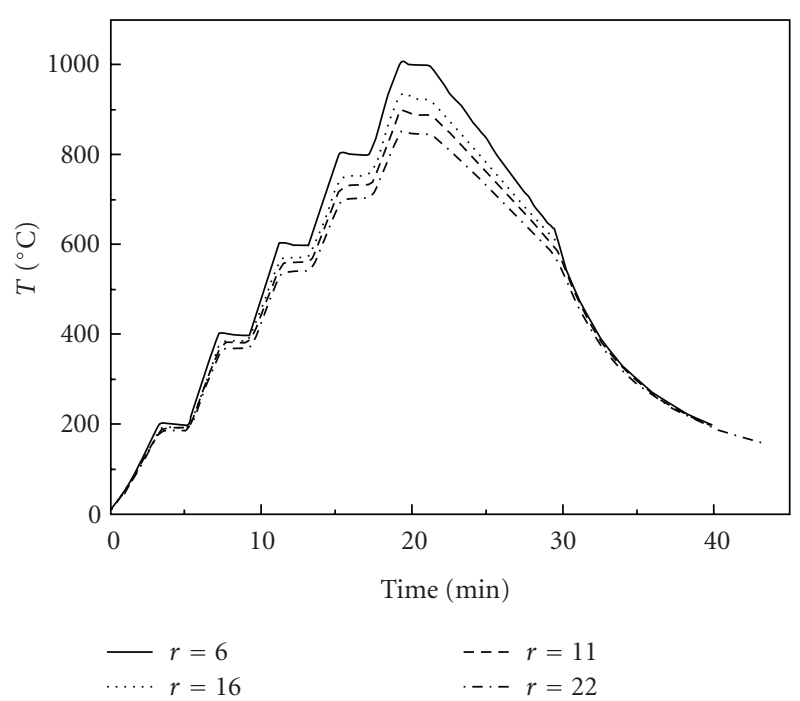

(a) At different radial distances $(h=0)$

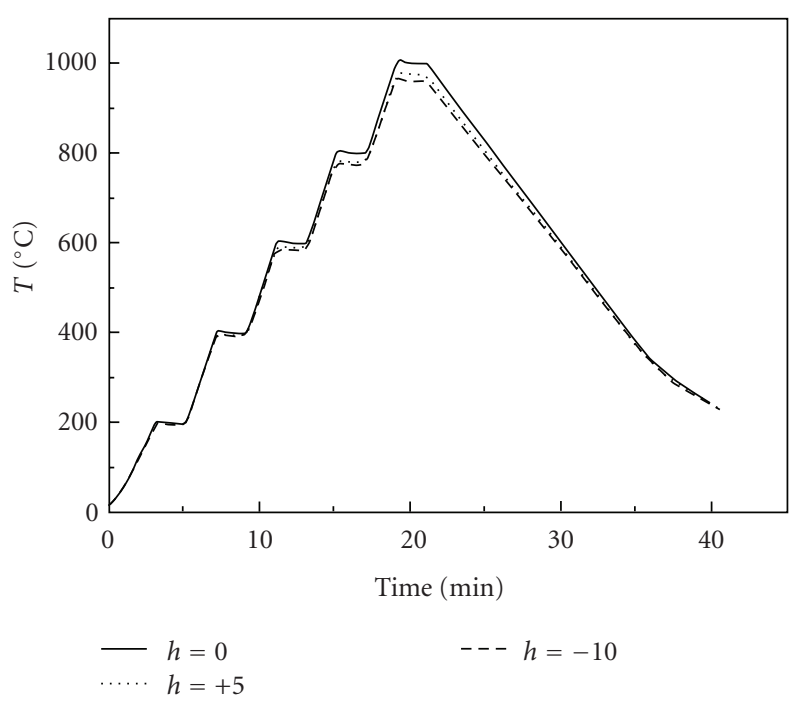

(b) At different heights $(r=22 \mathrm{~mm})$

FIgURE 4: $\mathrm{Al}_{2} \mathrm{O}_{3}$ : Temperature measurements.

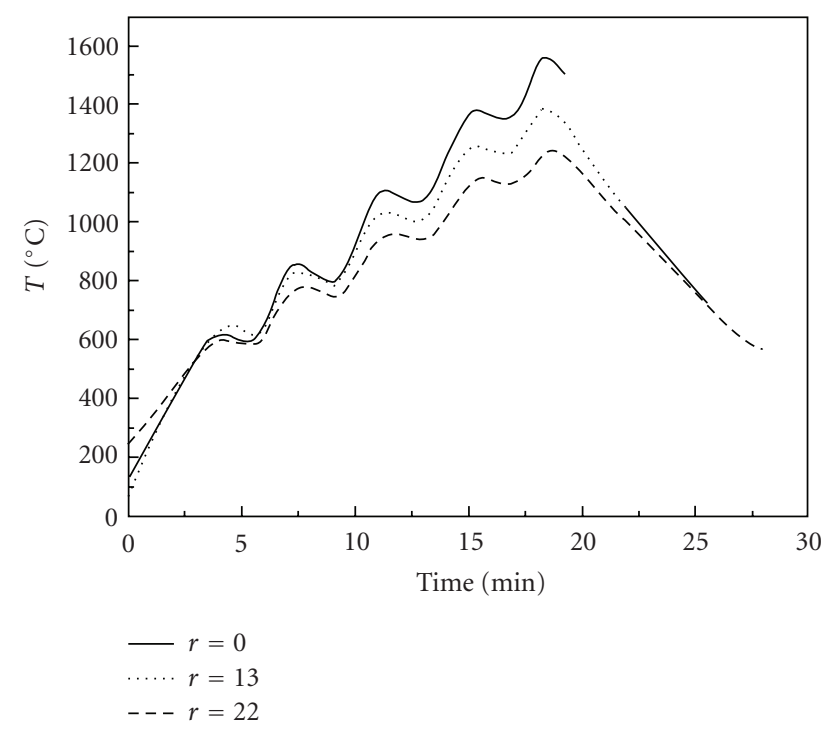

Figure 5: SiC: Temperature measurements at different radial distances $(h=0)$.

On the other hand, by successive trials, the voltage needed in calculations to get $1190^{\circ} \mathrm{C}$ as a stationary temperature at the place of interest was determined to be $2.85 \mathrm{~V}$. The corresponding temperature field is given in Figure 7(b), and plot (b) in Figure 8 gives the corresponding $T(r)$ function at $h=0$.

4.2.2. $\mathrm{Al}_{2} \mathrm{O}_{3}$ and $\mathrm{SiC}$. The same procedure described in the previous section was used for $\mathrm{Al}_{2} \mathrm{O}_{3}$ and $\mathrm{SiC}$ geometries: for each voltage associated with each temperature stage (Sections 4.1.2 and 4.1.3), calculations were made up to the stationary

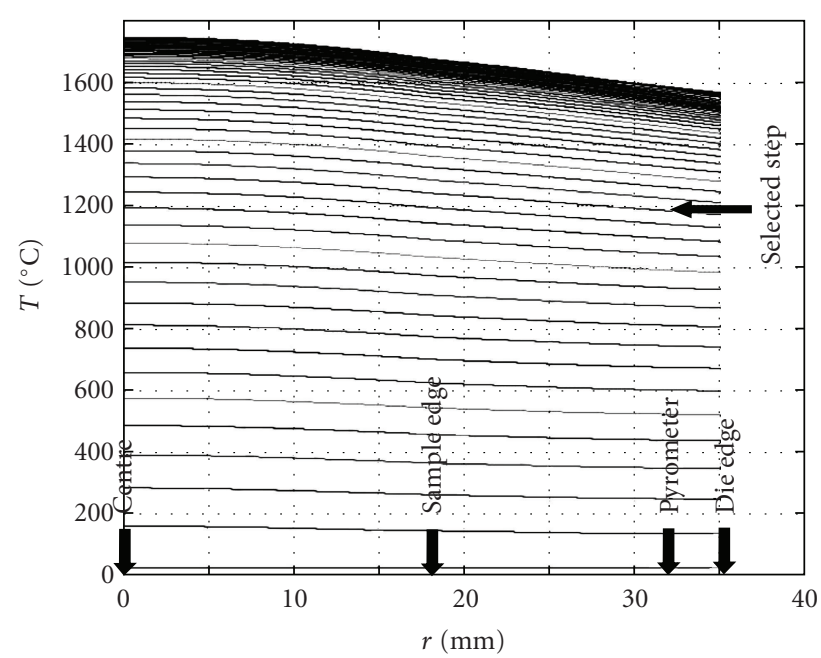

FIGURE 6: Radial variation of temperature in the horizontal symmetry plane calculated for the TiAl geometry and a voltage of $4.2 \mathrm{~V}$. One step over ten is represented.

state. For each one of these 9 calculations ( 5 for $\mathrm{Al}_{2} \mathrm{O}_{3}$ and 4 for $\mathrm{SiC}$ ), the step that yields a calculated temperature identical to the experimental temperature at $h=0$ and $r=22 \mathrm{~mm}$ was selected. Tables 2(b) and 2(c) commented in next section list the temperatures obtained at this selected step.

\section{Comparison and Discussion}

Tables 2(a), 2(b), and 2(c) give a comparison of calculated and measured temperatures. From these tables, it appears that calculated temperatures are relatively close to experimental ones: for $\mathrm{TiAl}, \mathrm{Al}_{2} \mathrm{O}_{3}$, and $\mathrm{SiC}$, the average 


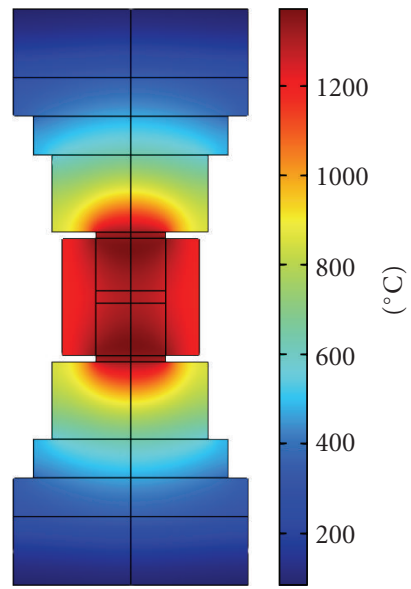

(a) For a $4.2 \mathrm{~V}$ voltage, at the step giving $1190^{\circ} \mathrm{C}$ where the pyrometer focuses

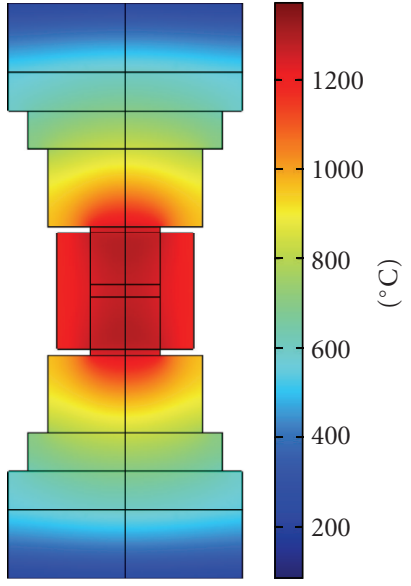

(b) For $2.85 \mathrm{~V}$ which gives $1190^{\circ} \mathrm{C}$ as a stationary temperature, at the same place

FIgUre 7: Field temperature of the "TiAl" geometry.

TABLE 2: Measured and calculated temperatures $\left({ }^{\circ} \mathrm{C}\right)$. The "\%" column gives the difference between both of them (temperatures in $\left.\mathrm{K}\right)$. Grey line: experimental temperature taken as reference (percentage is zero and without meaning). (a) TiAl, (b) $\mathrm{Al}_{2} \mathrm{O}_{3}$, (c) $\mathrm{SiC}_{\text {. }}$

(a)

\begin{tabular}{lccc}
\hline & Measurements & Calculations & $\%$ \\
\hline$r=32$ & 1190 & 1190 & - \\
$r=9$ & $1330 \pm 20$ & 1297 & -2.06 \\
$r=0$ & $1327 \pm 20$ & 1302 & -2.17 \\
\hline
\end{tabular}

(b)

\begin{tabular}{cccccccccccccccccc}
\hline & & \multicolumn{3}{c}{ Stage 1 } & \multicolumn{3}{c}{ Stage 2 } & \multicolumn{3}{c}{ Stage 3 } & \multicolumn{3}{c}{ Stage 4 } & \multicolumn{3}{c}{ Stage 5 } \\
& & Meas. & Calc. & $\%$ & Meas. & Calc. & $\%$ & Meas. & Calc. & $\%$ & Meas. & Calc. & $\%$ & Meas. & Calc. & $\%$ \\
\hline$h=0$ & $r=22$ & 190 & 190 & - & 364 & 364 & - & 536 & 536 & - & 693 & 693 & - & 829 & 829 & - \\
& $r=16$ & 193 & 191 & -0.4 & 379 & 366 & -2.0 & 557 & 541 & -1.9 & 718 & 704 & -1.4 & 872 & 849 & -2.0 \\
& $r=11$ & 190 & 191 & +0.2 & 382 & 368 & -2.1 & 564 & 548 & -1.9 & 736 & 718 & -1.8 & 904 & 875 & -2.5 \\
& $r=6$ & 196 & 192 & -0.9 & 400 & 371 & -4.3 & 596 & 555 & -4.7 & 789 & 732 & -5.4 & 989 & 902 & -6.9 \\
\multicolumn{1}{r}{$r=22$} & $h=+5$ & 196 & 190 & -1.3 & 392 & 364 & -4.2 & 586 & 536 & -5.8 & 772 & 693 & -7.6 & 964 & 831 & -10.8 \\
& $h=-10$ & 196 & 190 & -1.3 & 392 & 364 & -4.3 & 579 & 537 & -4.9 & 768 & 695 & -7.0 & 950 & 834 & -9.5 \\
\hline
\end{tabular}

(c)

\begin{tabular}{cccccccccccccc}
\hline & & \multicolumn{3}{c}{ Stage 1 } & \multicolumn{3}{c}{ Stage 2 } & \multicolumn{3}{c}{ Stage 3 } & \multicolumn{3}{c}{ Stage 4 } \\
& & Meas. & Calc. & $\%$ & Meas. & Calc. & $\%$ & Meas. & Calc. & $\%$ & Meas. & Calc. & $\%$ \\
\hline$h=0$ & $r=22$ & 583 & 583 & - & 750 & 750 & - & 939 & 939 & - & 1133 & 1133 & - \\
& $r=13$ & 622 & 589 & -3.7 & 783 & 763 & -1.9 & 1000 & 963 & -2.9 & 1233 & 1172 & -4.1 \\
& $r=0$ & 600 & 590 & -1.1 & 800 & 769 & -2.9 & 1078 & 976 & -7.5 & 1350 & 1191 & -9.8 \\
\hline
\end{tabular}

differences between calculated and experimental values are $-2.2 \%,-2.2 \%$ (standard deviation: $2.8 \%$ ) and $-4.2 \%$ (standard deviation: $2.8 \%$ ), respectively. Therefore, the different simplifications assumed (Section 3.3.2) have a limited effect and can be justified a posteriori. It can be pointed out that as for Anselmi-Tamburini et al. [6] who did not take into account thermal resistances or Vanmeensel et al. [7] who factored them in, differences are systematically negative (except for one value among the 35 comparisons). Whatever the electrical resistivity of the material, lower ( $\mathrm{TiAl}$ ) or higher $\left(\mathrm{Al}_{2} \mathrm{O}_{3}\right)$ than the graphite die, calculations maintain the same result quality. Besides, irrespective of the assembly shape (narrow part between punches and spacers or not, see Figures 2(a) and 2(b)), calculations give similar results in both cases.

Generally, SPS compactions are not achieved under thermodynamic equilibrium conditions. In the three situations investigated, temperature stages do not correspond to stationary states, that is, they are too short. For example, in the 


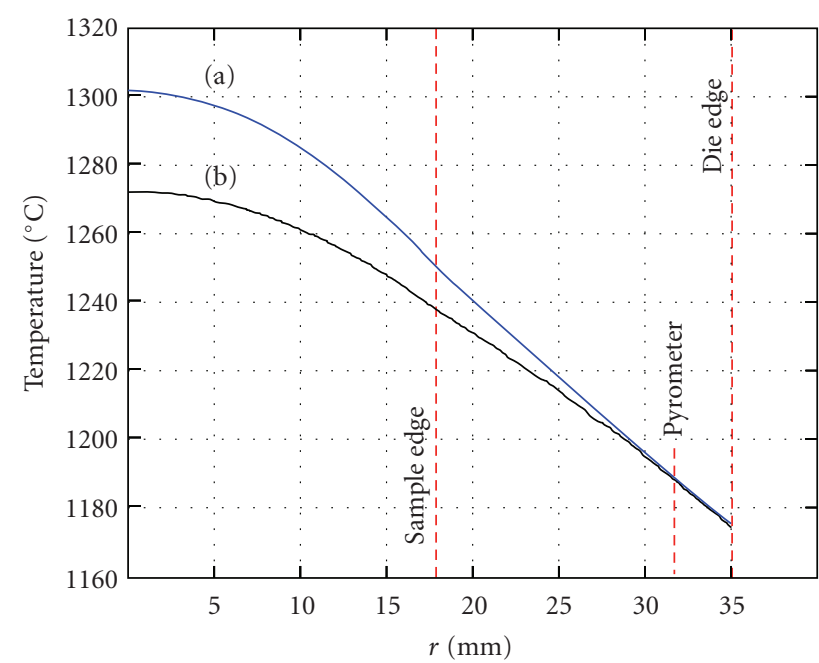

FIgURE 8: Radial variation of temperature $T(r)$ at $h=0$. (a) plot from Figure 7(a), (b) Plot from Figure 7(b).

TiAl case, with the $4.2 \mathrm{~V}$ voltage maintained for 2-minutes holding time, calculations give a stationary temperature of $1581^{\circ} \mathrm{C}$, that is, $391^{\circ} \mathrm{C}$ above the experimental temperature $\left(1190^{\circ} \mathrm{C}\right)$. On the contrary, a $2.85 \mathrm{~V}$ voltage is needed in the calculation to get a $1190^{\circ} \mathrm{C}$ stationary temperature. In this case, the temperature difference between the centre of the sample and the hole where the pyrometer is measering is unsurprisingly lower: $80^{\circ}$ in comparison, $112^{\circ}$ (Figure 8 ) and the sample temperature is less satisfactorily reflected in the calculation. The best agreement with experimental results is achieved with calculations performed under nonequilibrium conditions, a situation really reflecting what happens during the SPS process.

As a matter of fact, its nonequilibrium feature led to the choice of our method which consists in calculating step by step the temperature for a given voltage deduced from experiments and to select the step providing a calculated temperature equal to the measured temperature at a particular place. Subsequently, it is possible to compare the experimental and calculated temperatures where thermocouples were positioned, and to evaluate the temperature from the calculations at any place. Moreover, some other data, as the field of current intensity, can be extracted from modelling.

The present modelling is based on physics of continuous media, and obviously situated at a mesoscopic scale with a randomisation of the microscopic mechanisms. For example, this accounts for the " $\mathrm{Al}_{2} \mathrm{O}_{3}$ " geometry, for which the discrepancies are lower in the symmetrical plane $(h=$ 0 ), where the microscopic state is probably close to the average. This mesoscopic modelling allows a correlation at a macroscopic scale and thus its utilisation as a predictive tool for the industrial mastery of the process. It also provides comparative data for calculations at the microscopic and even nanoscopic scales ( $a b$ initio atomistic calculations...).

At least, it should be pointed out that this method does not allow for a direct prediction of the sample temperature without a first experiment allowing the determination of the tension. To achieve this goal, new calculations are being made using as input a time increasing voltage similar to the experimental one.

\section{Conclusion}

In this paper, finite elements calculations of the temperature field in samples and dies during a Spark Plasma Sintering experiment have been presented. These calculations were performed using a conducting material (TiAl), an insulating material $\left(\mathrm{Al}_{2} \mathrm{O}_{3}\right)$, and a material with intermediate conductivity $(\mathrm{SiC})$ and with various geometries of the encapsulating system. This method is based on the selection of the step reflecting the external temperature which is measured by an external pyrometer. The results were validated by comparison with experimental temperatures either measured by thermocouples or determined by the activation of a phase transition.

A good consistency, with a discrepancy lower than $5 \%$, was found between the calculated and measured temperatures irrespective of place, assembly geometry, and conductivity of the material. The temperature difference between the external wall of the die and the sample is quite elevated, higher than $100^{\circ} \mathrm{C}$. Since the SPS apparatus allows only the measurement of this external temperature, these calculations appear to be the only way to determine in advance the right external SPS temperature corresponding to the sample temperature desired. They should also support the evaluation of the temperature gradient in samples with a complex geometry.

\section{Acknowledgments}

The authors would like to thank Marc Thomas with DMMPONERA (Châtillon, France) for SEM images that allowed the temperature determination in TiAl samples and for fruitful discussions. They are also thankful for the PNF2 (Plateforme Nationale de Frittage Flash/CNRS in Toulouse, France) which provides SPS facilities.

\section{References}

[1] Z. A. Munir, U. Anselmi-Tamburini, and M. Ohyanagi, "The effect of electric field and pressure on the synthesis and consolidation of materials: a review of the spark plasma sintering method," Journal of Materials Science, vol. 41, no. 3, pp. 763-777, 2006.

[2] H. Conrad, A. F. Sprecher, W. D. Cao, and X. P. Lu, "Electroplasticity-the effect of electricity on the mechanical properties of metals," Journal of Materials Science, vol. 42, no. 9, pp. 28-33, 1990.

[3] W. Yucheng and F. Zhengyi, "Study of temperature field in spark plasma sintering," Materials Science and Engineering B, vol. 90, no. 1-2, pp. 34-37, 2002.

[4] K. Matsugi, H. Kuramoto, T. Hatayama, and O. Yanagisawa, "temperature distribution at steady state under constant current discharge in spark sintering process of $\mathrm{Ti}$ and $\mathrm{Al}_{2} \mathrm{O}_{3}$ 
powders," Journal of Materials Processing Technology, vol. 146, no. 2, pp. 274-281, 2004.

[5] A. Zavaliangos, J. Zhang, M. Krammer, and J. R. Groza, "Temperature evolution during field activated sintering," Materials Science and Engineering A, vol. 379, no. 1-2, pp. 218 228, 2004.

[6] U. Anselmi-Tamburini, S. Gennari, J. E. Garay, and Z. A. Munir, "Fundamental investigations on the spark plasma sintering/synthesis process: II. Modeling of current and temperature distributions," Materials Science and Engineering A, vol. 394, no. 1-2, pp. 139-148, 2005.

[7] K. Vanmeensel, A. Laptev, J. Hennicke, J. Vleugels, and O. van der Biest, "Modelling of the temperature distribution during field assisted sintering," Acta Materialia, vol. 53, no. 16, pp. 4379-4388, 2005.

[8] G. Molénat, M. Thomas, J. Galy, and A. Couret, "Application of spark plasma sintering to titanium aluminide alloys," Advanced Engineering Materials, vol. 9, no. 8, pp. 667-669, 2007.

[9] H. Inui, M. H. Oh, A. Nakamura, and M. Yamaguchi, "Ordered domains in TiAl coexisting with $\mathrm{Ti}_{3} \mathrm{Al}$ in the lamellar structure of Ti-rich TiAl compounds," Philosophical Magazine A, vol. 66, no. 4, pp. 539-555, 1992.

[10] S. Zghal, S. Naka, and A. Couret, "Quantitative TEM analysis of the lamellar microstructure in TiAl based alloys," Acta Materialia, vol. 45, no. 7, pp. 3005-3015, 1997.

[11] I. Ohnuma, Y. Fujita, H. Mitsui, K. Ishikawa, R. Kainuma, and K. Ishida, "Phase equilibria in the Ti-Al binary system," Acta Materialia, vol. 48, no. 12, pp. 3113-3123, 2000.

[12] A. Couret, G. Molénat, J. Galy, and M. Thomas, "Microstructures and mechanical properties of TiAl alloys consolidated by spark plasma sintering," Intermetallics, vol. 16, no. 9, pp. 11341141, 2008.

[13] http://www.hightempmetals.com/techdata/hitempInconel617 data.php, 2008.

[14] http://www.hightempmetals.com/techdata/hitempInconel600 data.php, 2008.

[15] M. Perez-Bravo, Nuevos intermetálicos gamma-TiAl: estudio $y$ optimización microestructural para su aplicación en aeronáutica, Ph.D. thesis, Universidad del Pais Vasco (UPV/EHU), 2005.

[16] http://www.matweb.com/search/SpecificMaterial.asp? bassnum=BCSC2A, 2008.

[17] http://www.matweb.com/search/SpecificMaterial.asp? bassnum=BA1A, 2008.

[18] D. Lundström, B. Karlsson, and M. Gustavsson, "Anisotropy in thermal transport properties of cast $\gamma$-TiAl alloys," Zeitschrift für Metallkunde, vol. 92, no. 11, pp. 1203-1212, 2001.

[19] D. Veeraraghavan, U. Pilchowski, B. Natarajan, and V. K. Vasudevan, "Phase equilibria and transformations in Ti-(2552) at.\% $\mathrm{Al}$ alloys studied by electrical resistivity measurements," Acta Materialia, vol. 46, no. 2, pp. 405-421, 1998. 

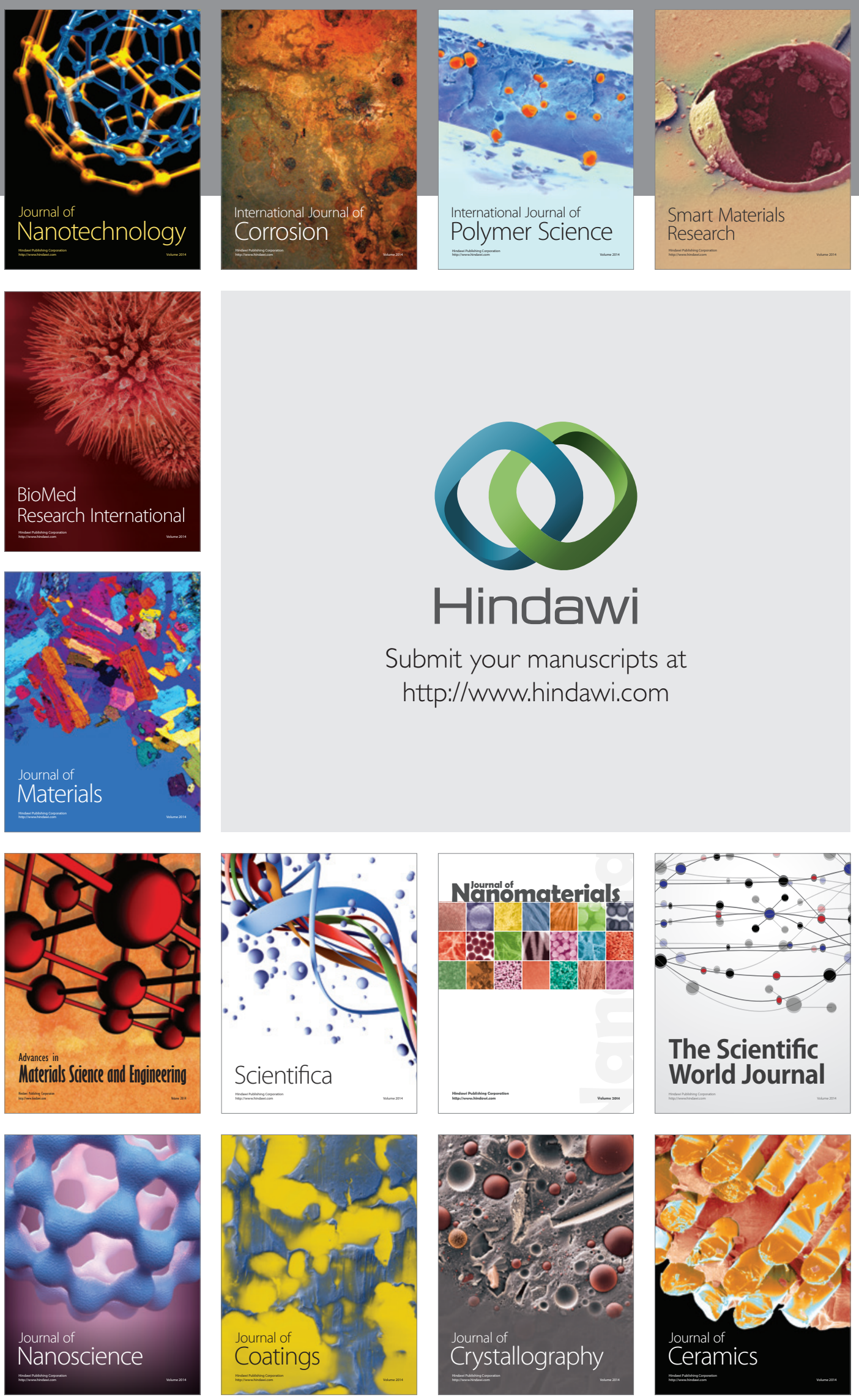

The Scientific World Journal

Submit your manuscripts at

http://www.hindawi.com

\section{World Journal}

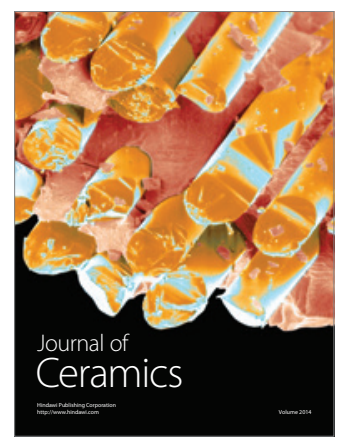

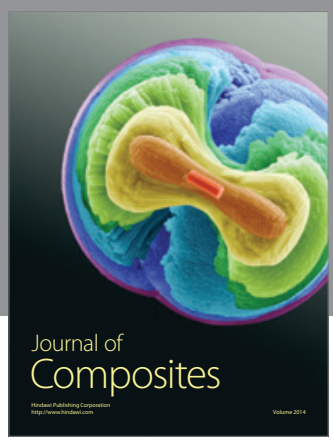
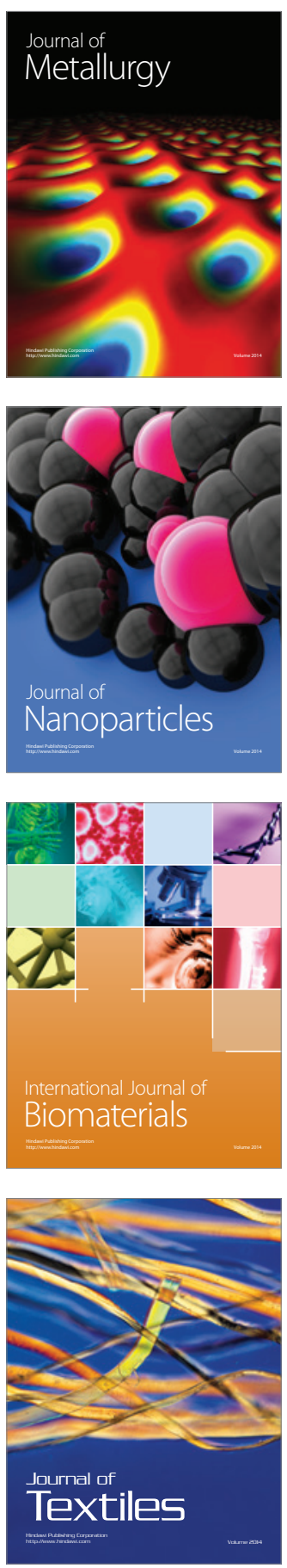